\title{
Modeling the influences of aerosols on pre-monsoon circulation and rainfall over Southeast Asia
}

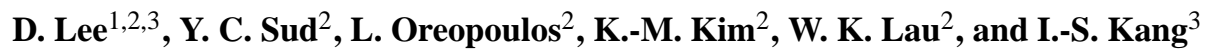 \\ ${ }^{1}$ GESTAR, Morgan State University, Baltimore, Maryland, USA \\ ${ }^{2}$ Earth Sciences Division, NASA Goddard Space Flight Center, Greenbelt, Maryland, USA \\ ${ }^{3}$ School of Earth and Environmental Sciences, Seoul National University, Seoul, South Korea \\ Correspondence to: D. Lee (dongmin.lee@ nasa.gov)
}

Received: 30 October 2013 - Published in Atmos. Chem. Phys. Discuss.: 16 December 2013

Revised: 27 May 2014 - Accepted: 29 May 2014 - Published: 4 July 2014

\begin{abstract}
We conduct several sets of simulations with a version of NASA's Goddard Earth Observing System, version 5, (GEOS-5) Atmospheric Global Climate Model (AGCM) equipped with a two-moment cloud microphysical scheme to understand the role of biomass burning aerosol (BBA) emissions in Southeast Asia (SEA) in the pre-monsoon period of February-May. Our experiments are designed so that both direct and indirect aerosol effects can be evaluated. For climatologically prescribed monthly sea surface temperatures, we conduct sets of model integrations with and without biomass burning emissions in the area of peak burning activity, and with direct aerosol radiative effects either active or inactive. Taking appropriate differences between AGCM experiment sets, we find that BBA affects liquid clouds in statistically significantly ways, increasing cloud droplet number concentrations, decreasing droplet effective radii (i.e., a classic aerosol indirect effect), and locally suppressing precipitation due to a deceleration of the autoconversion process, with the latter effect apparently also leading to cloud condensate increases. Geographical re-arrangements of precipitation patterns, with precipitation increases downwind of aerosol sources are also seen, most likely because of advection of weakly precipitating cloud fields. Somewhat unexpectedly, the change in cloud radiative effect (cloud forcing) at surface is in the direction of lesser cooling because of decreases in cloud fraction. Overall, however, because of direct radiative effect contributions, aerosols exert a net negative forcing at both the top of the atmosphere and, perhaps most importantly, the surface, where decreased evaporation triggers feedbacks that further reduce precipitation. Invoking the approximation that direct and indirect aerosol ef-
\end{abstract}

fects are additive, we estimate that the overall precipitation reduction is about $40 \%$ due to the direct effects of absorbing aerosols, which stabilize the atmosphere and reduce surface latent heat fluxes via cooler land surface temperatures. Further refinements of our two-moment cloud microphysics scheme are needed for a more complete examination of the role of aerosol-convection interactions in the seasonal development of the SEA monsoon.

\section{Introduction}

Use of fossil fuels for ever-growing energy demands, particularly in developing countries, has led to increased concentrations of aerosol-laden combustion by-products, especially in the planetary boundary layer (PBL) (Roelofs, 2013). Moorthy et al. (2013) estimate that aerosols over India have been increasing at the rate of $2-4 \%$ per year over the last three decades, resulting in doubled aerosol optical depth (AOD) in India's lower atmosphere. Similar changes are expected over other regions such as Southeast Asia (SEA). Biomass burning (BB) is an age-old method of disposing of agricultural trash (Taylor, 2010) and in SEA, it occurs primarily during the spring season (i.e., February-March-April, FMA; Gautam et al., 2013). Over SEA, the combustion by-products released into the atmosphere contain large quantities of biogenic aerosol/carbon particles whose quantitative estimates are being tabulated with extensive measurements (Wiedinmyer et al., 2011).

Biomass burning aerosol (BBA) can affect the atmospheric circulation in several ways. BBA absorbs and reflects 
Table 1. Experimental designs for our GEOS-5 AGCM simulations. "Zero" stands for zero BB emissions over the green dash box region of Fig. 1a, "High" for high (year 2007, Fig. 1b) emissions. Symbols under aerosol direct effect and indirect effect indicate experiments with $(\mathrm{O})$ and without $(\mathrm{X})$ the effect.

\begin{tabular}{llcc}
\hline & BB & Direct effect & Indirect effect \\
\hline HighBoth & High & O & O \\
ZeroBoth & Zero & O & O \\
HighInd & High & X & O \\
ZeroInd & Zero & X & O \\
\hline
\end{tabular}

solar radiation, thereby reducing the solar radiation reaching the surface, reducing surface sensible and latent heat fluxes (Ramanathan et al., 2005). Chung and Ramanathan (2006) showed the so-called "Atmospheric Brown Cloud" decreases the surface solar radiation flux, which reduces surface evaporation while also weakening latitudinal sea surface temperature (SST) gradients and stabilizing the troposphere, causing monsoon rainfall decreases. On the other hand, absorption of solar radiation at the aerosol level warms the local atmosphere, inducing elevated heating that can invigorate air mass convergence near the surface and, with the addition of sensible and latent heat, can make the PBL unstable enough to promote moist convection (Lau et al., 2006; Lau and Kim, 2006, 2014). The net outcome of the resulting complex feedback interactions may either increase or decrease local rainfall (Meehl et al., 2008). Furthermore, many particles from $\mathrm{BB}$ emission are active cloud condensation nuclei (CCN) (Petters et al., 2009). Hence more BB emission leads to more $\mathrm{CCN}$ and ice nuclei (IN) and thereby more cloud particles. If we assume that the net condensate production is solely governed by cloud-scale dynamics, more CCN would imply larger numbers but smaller cloud droplets and thereby an increase in cloud albedo (Twomey, 1977). Smaller cloud particles would also hamper the autoconversion of cloud water into precipitation, so the presence of $\mathrm{BB}$ sources is expected to reduce the precipitation production rate and increase cloud lifetime (Albrecht, 1989). However, this process is only applicable to warm rain. Observations show that cold and mixed cloud regimes have complicated responses, as summarized in Tao et al. (2012, Table 1). Li et al. (2011), with extensive observational analysis in the Atmospheric Radiation Measurement (ARM) site at Southern Great Plains, show that cloud-top height and thickness increase with aerosol concentration in mixed-phase clouds and rain increases with aerosol concentration in deep clouds, but declines in clouds that have low liquid-water content.

Satellite data reveal that during FMA, the SEA region exhibits the highest aerosol concentrations, an order of magnitude greater than that in the summer monsoon May-JuneJuly-August (MJJA) season because of more BBA sources during dry FMA (Ichoku et al., 2008; Lin et al., 2009) and less wet scavenging of aerosols compared to rainy MJJA. Accordingly, aerosol optical depth and aerosol-activated cloud particle numbers are expected to be much larger in FMA than MJJA. This is the main reason for focusing this investigation of BBA direct and indirect effects on FMA and the transition month of May. Our working hypothesis is that high aerosol number concentration in FMA has a strong influence on the radiative forcing, circulation, and precipitation of the local and surrounding region. Important factors would be aerosolcloud-radiation interactions. The cloud cover over SEA is generally composed of stratiform, low-altitude clouds associated with frontal systems that originate in China (Hsu et al., 2003). The major type of precipitation would be warm rainfall in the focused season.

Direct and indirect effects of aerosols are intrinsically interactive, and therefore their combined effects can be very different from their linear sum. Even though the fundamental physics of aerosol direct and indirect effects is reasonably well understood, uncertainty of aerosol data under cloudy conditions and complexities in coupling the aerosol-cloudradiation interactions prohibit a better understanding of the impact of these processes. For example, a positive relationship between AOD and total cloud cover (TCC) was shown in satellite data (Kaufman et al., 2005; Kaufman and Koren, 2006), but the dominant contribution to the AOD-TCC relationship have been attributed to aerosol swelling in humid air rather than the direct effects of aerosols on the cloud fields (Quass et al., 2010).

Aerosol-cloud interaction effects on South Asia to East Asia circulation and monsoons have been the subject of investigations with regional models (Wu et al., 2013; Lim et al., 2014) as well as global climate models (Bollasina et al., 2011; Ganguly et al., 2012; Guo et al., 2013). Our current cloud physics scheme, Microphysics of clouds with Relaxed Arakawa-Schubert moist convection upgraded with prognostic aerosol-cloud interactions (McRAS-AC; Sud et al., 2013), has indirect effect simulation capabilities, and has been implemented in the GEOS-5 AGCM (Rienecker et al., 2008). It provides an opportunity to perform simulation studies to systematically assess the influence of BBA on rainfall and circulation in SEA. Clearly, constrained model simulations are one plausible way to better distinguish between the roles of direct and indirect effects and their interactive influences that depend on circulation, cloud types, and aerosoldependent cloud microphysics. While in principle these effects can be properly simulated only with a coupled oceanatmosphere model, as a first step we use an AGCM with prescribed monthly SSTs and with aerosol emission anomalies prescribed from the Quick Fire Emissions Dataset (QFED) data set (see Sect. 2.1). This way we can isolate the influence of BBA over land by comparative assessments of circulation and rainfall changes in neighboring regions.

In this endeavor, we perform a comprehensive model simulation study with the physically interactive aerosol-cloudradiation treatment of McRAS-AC as implemented in the 
GEOS-5 AGCM, in order to better understand the spatiotemporal modulation of the SEA pre-monsoon season by BBA. Section 2 describes the data set, model and experimental design; results and a summary are presented in Sects. 3 and 4, respectively.

\section{Data, model and experimental design}

\subsection{Data sets for aerosol effect analysis}

$\mathrm{BB}$ is a major source of primary emissions of carbonaceous aerosols over the SEA region. QFED (Darmenov and da Silva, 2013) was developed to meet the needs of the NASA Goddard Earth Observing System Model (GEOS) with regard to atmospheric constituent modeling and data assimilation of BB events. QFED is based on global gridded fire radiative power, derived from the Moderate Resolution Imaging Spectroradiometer (MODIS) Level 2 fire product. QFED is used not only as a BB inventory for the global Goddard Chemistry Aerosol Radiation and Transport (GOCART, Chin et al., 2002, Colarco et al., 2010) model in the GEOS-5 system, but also as an index indicating high BB days for our composite analysis. Version 2.2 used in this study covers the period from January 2003 to December 2010. The QFED Level-3 products are available at $0.3125 \times 0.25^{\circ}$ horizontal resolution, but are degraded to $2.5 \times 2.0$ degree for use in the present model simulation. The $1^{\circ}$ MODIS Aqua level 3 daily product (MYD03_D3) is used for aerosol optical depth (Chu et al., 2002) and liquid cloud effective radius (Platnick et al., 2003). The data cover the period from July 2002 to present. For precipitation, $1^{\circ}$ daily Global Precipitation Climatology Project (GPCP-1DD; Huffman et al., 2001) data are used, covering the period October 1996 to present.

\subsection{GEOS-5 AGCM with double moment microphysics and updated radiation}

The numerical model used for this study is the GEOS5 AGCM, version Fortuna 2.5 documented by Molod et al. (2012). In the current application, McRAS-AC replaces the cloud scheme of the baseline model. McRASAC synthesizes the initial version of McRAS (described in Sud and Walker, 1999, 2003) with subsequently developed aerosol-cloud interaction microphysics described in Sud and Lee (2007). The latest modification to McRAS-AC includes the addition of Barahona and Nenes (2009a, b) ice nucleation for mixed phase and ice phase clouds, as well as Fountoukis and Nenes (2005) liquid droplet formation. The precipitation parameterization remains as before, namely Sud and Lee (2007) for the liquid phase and Sundqvist (1988) for the mixed and ice phases. In-cloud evaporation, precipitation and self-collection of cloud water are parameterized according to Sud and Lee (2007), employing a reformulated version of the Seifert and Beheng (2001, 2006) parameterization to handle the much thicker cloud layers encoun- tered in a coarse resolution GCM. These algorithms work seamlessly across widely varying vertical model-layer thicknesses. Any change in the cloud water substance mass by condensation/deposition and/or collection by precipitation works interactively through an implicit backward numerical integration that approximates the solution of the basic nonlinear coupled differential equations for the cloud source and sink terms of the mass balance tendency equation. Despite using the observationally based Sundqvist (1988) equations for the mixed phase and ice phase precipitation tendencies, the implementation of the Barahona and Nenes (2009a, b) ice nucleation and the Bergeron-Findeisen cloud water-toice mass transfer (Rotstayn et al., 2000) allows for a reasonable separation of cloud liquid and ice mass fractions with their accompanying liquid and ice particle number concentrations. Homogenous freezing of in-cloud liquid droplets surviving below $-38^{\circ} \mathrm{C}$ is enforced by assuming instantaneous freezing. Aerosol-cloud interactions are implemented into both stratiform (large-scale) clouds, and convective towers topped by detraining convective anvils that transform into large-scale clouds at a prescribed timescale of an hour. Sud et al. (2013) provides a much more comprehensive discussion of McRAS-AC (including treatment of the different cloud types) and its comparative performance against the cloud scheme of the baseline model. That study also includes sensitivity studies with an interactive aerosol module and modified aerosol size distribution. The model used in the current study contains all the upgrades outlined above. The CFMIP Observation Simulator Package (COSP, http: //cfmip.metoffice.com/COSP.html) is also employed online in our experiments. Because of the significant differences between the way clouds are observed and represented in models, a "satellite simulator" facilitates proper comparison and validations of the key simulated cloud and radiation fields against observations (Klein et al., 2013). The GOCART module provides prognostic aerosols fields consisting of five aerosol species with fifteen modes. There are five modes of dust and sea salt sorted in different particle size bins; there are two modes of organic and black carbon to sort hydrophilic and hydrophobic particles; and one mode of sulfate particles. All aerosol modes are assumed to be "externally" mixed. The GOCART module runs interactively and provides prognostic aerosol fields within the AGCM.

Accurate radiation calculations are also very important for properly simulating aerosol direct/indirect effect. Our means of calculating realistic cloud radiative effect (CRE) is the advanced RRTMG radiative transfer package (Clough et al., 2005) equipped with a subcolumn generator in the GEOS5 AGCM. RRTMG can be run in Monte Carlo Independent Column Approximation (McICA) mode (Pincus et al., 2003) that operates on subcolumns with either clear or completely overcast cloud layers produced by a cloud generator. Whether the cloud condensate in a particular layer is different from subcolumn to subcolumn depends on the specific assumptions about horizontal cloud heterogeneity as 

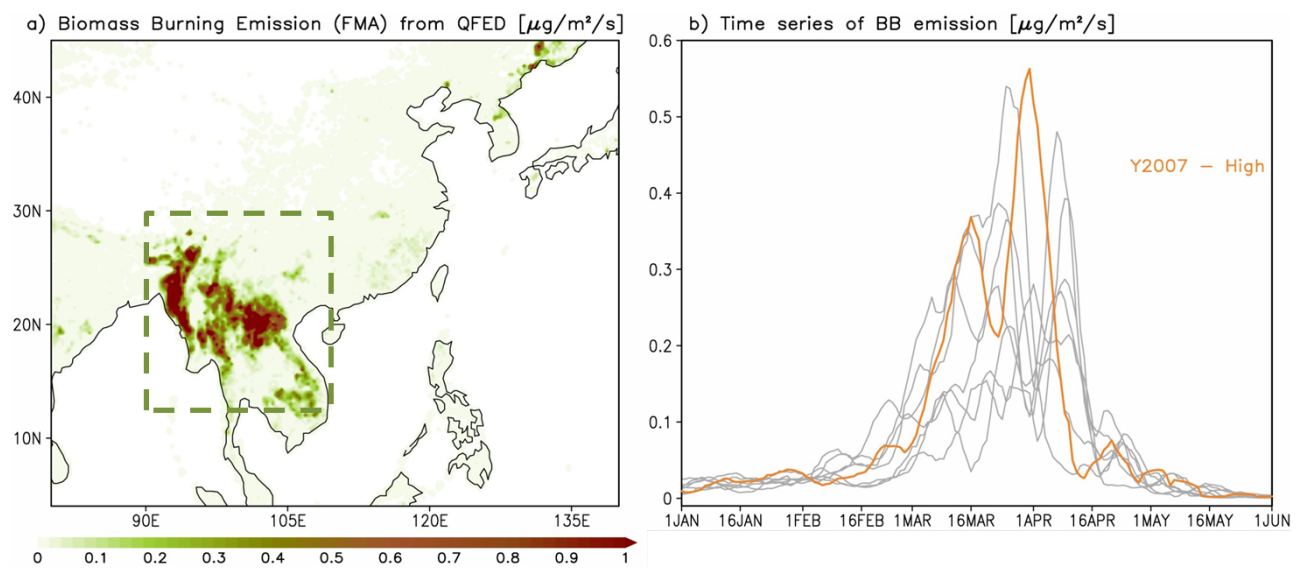

Figure 1. QFED BB emission data (OC data is used for this figure, unit of $\mu \mathrm{g} \mathrm{m}^{-2} \mathrm{~s}^{-1}$ ). (a) February-March-April mean and (b) averaged time series for dashed box area. Time series are smoothed by a 7-day moving average. Orange line represents data for year 2007 for high BB simulation experiments. Other years are plotted in gray.

determined by distributions of condensate specified within the cloud generator. A prior implementation of McRAS-AC (Sud et al., 2013) used cloud water path scaling to account for the radiative effects of subgrid scale cloud water inhomogeneity. More detailed discussions about RRTMG in the GEOS-5 AGCM can be found in Oreopoulos et al. (2012).

\subsection{Experimental design}

In order to investigate BBA effects on SEA climate, several observation-inspired experiments with and without BB emission over SEA are designed. Figure 1a shows the climatological amount of carbonaceous aerosol emission from BB during FMA averaged over 8 years from 2003 to 2010, and Fig. 1b depicts the time series of the boxed area. The QFED data set described earlier was used for this figure. Massive BB emissions occur during FMA in the eastern regions of Cambodia, Myanmar, Laos, and northern Thailand with peaks in March. Figure 1b shows large temporal variations of BB emissions. It could be high in one month and also could become near zero in another month.

To isolate the potential BBA effects, the AGCM experiments were performed with climatological SSTs to eliminate large-scale forcing (e.g., El Niño events) influences due to SST variability. Moreover, to separate the signal from the model's own internal variability, multi-member ensemble simulations were performed. Each simulation-set consists of a 10-member ensemble covering the early January to late August period; each runs starts with different initial conditions taken from the model runs used in Sud et al. (2013). To estimate the signal of aerosol effects on climate variability, we conducted experiments with "Zero" BB emission over the green dash box region (Fig. 1a) and compared them to experiments with "High" BB emission in 2007. BB emissions outside of the boxed area and all other sources of aerosol were set to climatological means for both "High" and "Zero" emis- sion experiments. Such an "aerosol on" and "aerosol off" design is often used in aerosol-climate sensitivity studies (e.g., Lau et al., 2006; Wu et al., 2013) to better depict the aerosol signal, but this methodology has the drawback of making the comparison of simulations with observations difficult. Initial simulation sets using year-to-year emission data set did not yield statistically significant differences on circulation, while some sensitivity to enhanced emissions could be discerned in increased AODs, brightened liquid clouds and decreased rainfall. Clearly, by design, the differences between "High" and "Zero" emission experiments yield the effect of BBA, black carbon, organic carbon, and sulfate originating from the boxed area and in order to isolate statistically significant signals a Student's $t$ test is employed. We considered the differences exceeding the $95 \%$ confidence level in a difference field as statistically significant.

The differences between "HighBoth" and "ZeroBoth" simulations are a measure of the total BB effect. Here, "Both" means that the model's experimental setup includes both aerosol direct and indirect effects. The indirect-only simulations are denoted by "HighInd" and "ZeroInd" experiments. In these simulations, we neglect the aerosol direct effect by turning off aerosol radiative interactions globally, thereby allowing only the indirect effects of aerosols to operate on clouds and influence their radiative effects. HighInd minus ZeroInd differences therefore measure the strength of the BBA indirect effect. Finally, while not additive due to nonlinearities, comparing "Both" and "Ind" runs gives insight into the relative contributions of direct and indirect effects to the total aerosol effect. 


\section{Results}

\subsection{Comparison between model simulations and satellite observations}

Some insight on the effects of BB in SEA can be obtained by comparing high and climatological $\mathrm{BB}$ conditions in observations. We have constructed composites of MODIS Aqua Level 3 daily products (MYD03_D8) for 36 days of the highest BB emission index within the 2003 to 2010 period. The $\mathrm{BB}$ emission index is defined as the area average for the dashed box area in Fig 1a. Smoothed time series of the index is shown in Fig. 1b. Figure 2 shows comparisons between the high-emission days and the 8-year climatology of MODISAqua AOD (Fig. 2a) and liquid cloud effective radius ( $R_{\text {eff }}$, Fig. 2b). When BB is high in FMA over inland areas of SEA compared to normal days, anomalously high AOD appears over the northern part of SEA up to the coast of southern China. According to Lau and Kim (2014), low-level wind in the area carries BBA from the source region to southern China, resulting in the high BB AOD anomaly of Fig. 2a. According to the rightmost panel of Fig. 2b, the corresponding negative anomaly of $R_{\text {eff }}$ coincides with the region where a positive AOD anomaly exists. This is a classic manifestation of aerosol indirect effect whereby increased BBA reduces the size of cloud droplets by increasing $\mathrm{CCN}$ number concentration. Indeed, if the negative anomaly of $R_{\text {eff }}$ is related to aerosol, then the imprints of other aerosol indirect effects may also exist in other meteorological fields, such as the precipitation. Figure $2 \mathrm{c}$ compares composited daily GPCP precipitation for the enhanced BB days and the climatology. The difference plot reveals a negative precipitation anomaly over the aerosol source and its adjacent areas while in the vicinity of the east coast of China increased rainfall is observed. This can be interpreted in a Lagrangian framework, by the cloud holding more cloud water due to reduced autoconversion efficiency, but as the cloud advects downwind (i.e., towards the northeast direction), it eventually releases cloud water as precipitation far away from the source region. Higher BB emission days are selected from every year and compared with climatology to remove interannual variability and SST forcing and isolate the BBA effects. However, since large-scale SST forcings, such as El Nino, can simultaneously trigger a reduction in precipitation and an increase in aerosols (Tosca et al., 2010), it is necessary to study shifts in the precipitation pattern from AGCM simulations.

In order to evaluate the sensitivity of the AGCM to BBA variations, model output is compared to the satellite data analysis. Figure 3 shows the overall BBA-simulated sensitivity of the model as the difference between HighBoth and ZeroBoth experiments. Anomalies in $R_{\text {eff }}$ are obtained using COSP's MODIS simulator in the GEOS-5 AGCM for fair comparison with observations. For the 10-member ensemble mean, simulated AOD increases downwind (i.e., towards the northeast direction) of the BB source and correspond-

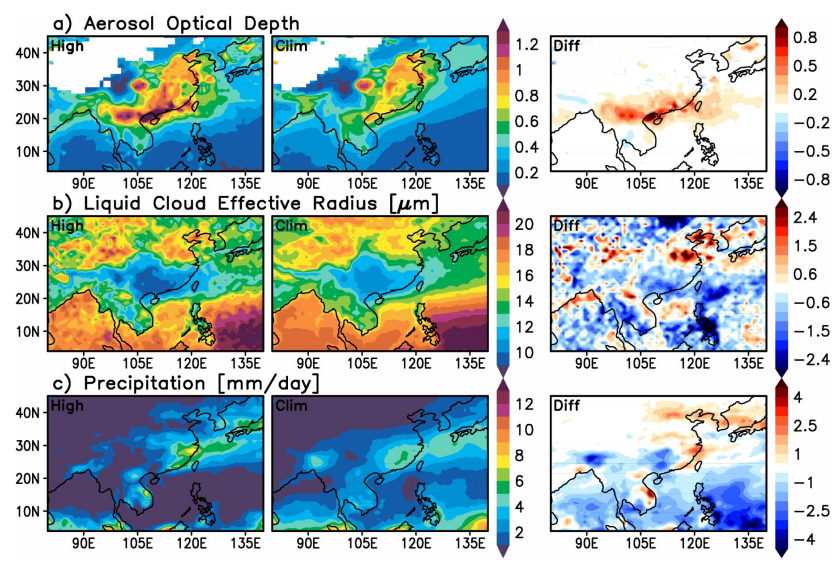

Figure 2. Composite analysis and differences (Diff) in (a) aerosol optical depth and (b) liquid cloud effective radius $(\mu \mathrm{m})$ from MODIS-Aqua retrievals, and (c) GPCP precipitation $\left(\mathrm{mm} \mathrm{day}^{-1}\right)$. High emission (left), climatology (middle) and differences: high minus climatology (right) panels respectively. Here 36 high-emission days and 8-year climatology data are used.

ingly $R_{\text {eff }}$ decreases. Not only are McRAS-AC AGCM simulations capable of simulating the response of cloud droplets to AOD, but the model's overall response exhibits reasonable spatial coherence with the composite maps of observation data (Fig. 2), particularly on the downwind side of the BB source. Wind vectors at $800 \mathrm{hPa}$ are plotted on Fig. 3a to explain an advection of BBA. For precipitation, the observations show a dipole-like anomaly pattern, namely overall decrease near source area and at eastern locations, and increase further east near the coast (Fig. 2c, Diff). In the model, on the other hand, the average BB signal on FMA precipitation materializes as a reduction in the precipitation of large areas south and east of the source region. Since SSTs were prescribed climatologically, less meaningful responses over the ocean is expected. Potential BBA effects on SEA premonsoon are investigated further in the following sections by taking appropriate differences of GEOS-5 experimental sets described earlier.

\subsection{BB effects on cloud microphysics and precipitation simulation}

One of the mechanisms that changes the nature and amount of precipitation is cloud microphysical processes as influenced by aerosols, widely known as the aerosol second indirect effect (Albrecht, 1989). This mechanism acts on the autoconversion rate that modulates the intensity of liquid precipitation. Our area of focus where precipitation decreases in MODIS analysis and model simulations is likely affected by BBA that are transported to southern China, where a persistent cloud band exists. In the model simulation the horizontal and vertical location of aerosol and the cloud band(s) are in close proximity, as seen in Fig. 4. The figure shows 


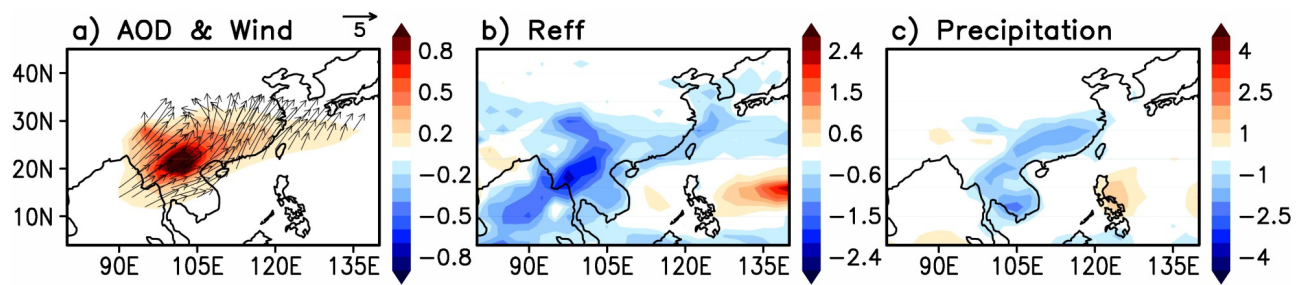

Figure 3. Same variables as in Fig. 2 but for HighBoth minus ZeroBoth differences of AGCM simulations. Panels show (a) aerosol optical depth, (b) liquid cloud effective radius $(\mu \mathrm{m})$ and precipitation rate $\left(\mathrm{mm} \mathrm{day}^{-1}\right)$ during the FMA time period. Vectors on (a) are wind vectors at $800 \mathrm{hPa}$ from HighBoth, only plotted where AOD increases.

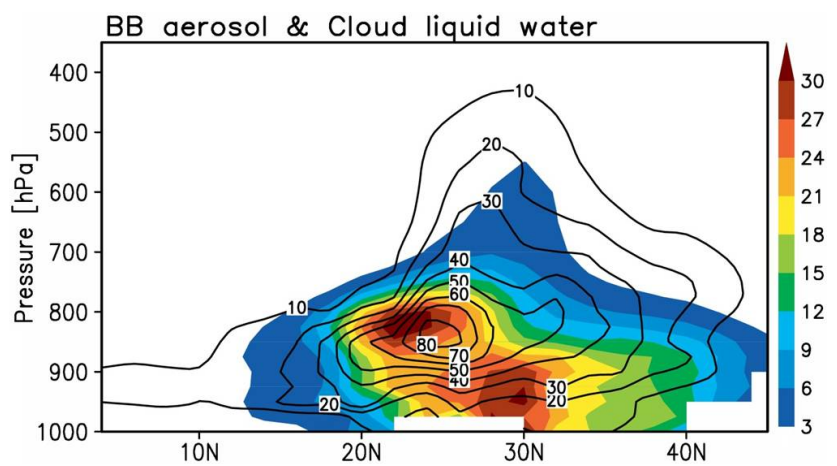

Figure 4. Vertical cross section of simulated mixing ratio of BBA (shading, $\mu \mathrm{g} \mathrm{kg}^{-1}$ ) and cloud liquid water (contour, $\mathrm{mg} \mathrm{kg}^{-1}$ ) in March in HighBoth simulations; zonal averaging is performed for 105 to $120^{\circ} \mathrm{E}$.

the vertical cross section of the BBA mixing ratio (shading) and cloud liquid water content (contour) for March, obtained from the HighBoth experiment in the vicinity of decreased precipitation as shown in Fig. 3c (105 to $120^{\circ}$ E). BBA are lifted aloft by topography (oriented in a north-south direction), and act as an additional source of $\mathrm{CCN}$ in pre-existing clouds which are mostly low-level (warm) and therefore of liquid phase at this particular location and time of the year.

In the model, BB produces sulfate and carbonaceous aerosols that can be activated as cloud droplets. Sulfate aerosols are highly soluble, while the carbonaceous aerosols have both hydrophobic and hydrophilic modes. Hydrophilic organic and black carbon aerosols have prescribed fractions of soluble mass $(0.25$ and 0.1$)$ so they also act as CCNs. Thus BBAs present at the level of developing liquid clouds also activate along with the background aerosols. Under conditions of massive $\mathrm{BB}$, the $\mathrm{CCN}$ number concentration increases greatly, yielding increased cloud drop number concentration and reduced cloud droplet sizes for constant cloud water. The underlying physics leading to the reduction in $R_{\text {eff }}$ is well captured by the model (Fig. 3b). Smaller droplets reduce the efficiency of autoconversion from cloud liquid water to rain, resulting in less precipitation. The double moment microphysics in McRAS-AC reduces autoconversion rate process via the parameterization,

$$
\left(\frac{\partial L_{\mathrm{c}}}{\partial t}\right)_{\text {auto }}=-K L_{\mathrm{c}}^{4} N_{\mathrm{c}}^{-2}
$$

where $L_{\mathrm{c}}$ is the cloud liquid water content $\left(\mathrm{kg} \mathrm{m}^{-3}\right), N_{\mathrm{c}}$ is the cloud drop number concentration $\left(\mathrm{m}^{-3}\right)$, and $K$ is an accumulated constant for autoconversion (see Eq. A.2 in Sud and Lee, 2007, with units of $\mathrm{kg}^{-3} \mathrm{~m}^{3} \mathrm{~s}^{-1}$ ). From Eq. (1), as $N_{\mathrm{c}}$ increases under the assumption of constant $L_{\mathrm{c}}$, the autoconversion rate decreases. The occurrence of this second aerosol indirect effect is shown by the model experiments. Monthly mean difference fields between HighBoth and ZeroBoth experiments from March to May are shown in Fig. 5 for AOD, $N_{\mathrm{c}}$, cloud liquid water path (LWP), precipitation and total cloud fraction. $N_{\mathrm{c}}$ has been vertically averaged from 900 to $750 \mathrm{hPa}$. Red (blue) color indicates positive (negative) anomaly with increasing BBA. Green contours delineate the areas where the change by BBA is significant at the $95 \%$ significance level, based on Student's $t$ test. Aerosols clearly increase due to BB emission with an annual peak in March, and so does the AOD anomaly. Since February is a dry season for the area, the analysis focuses on March, April and May, with the latter month delineating the onset of the East Asian monsoon. With BB occurring mainly in early spring, aerosol concentrations in May should not be affected much, so any signal in the meteorological fields for that month is potentially due to circulation and land surface changes induced by BB emissions in the preceding months. In the model we can decompose AOD anomaly by species. The difference of AOD between HighBoth and ZeroBoth experiments over the boxed area in Fig. 1 for the month of March is 0.6, 0.487 coming from organic carbon, 0.063 from sulfate, and 0.05 from black carbon. There is some amount of "background" sulfate in ZeroBoth $(\mathrm{AOD}=0.129)$, but organic and black carbon aerosols are mostly from BB emissions, so their AODs in ZeroBoth are quite small, 0.031 and 0.013 , respectively. Dust and sea salt aerosol presence are very small over the region with AODs less than 0.01.

As stated earlier, as the BBA loadings increase, grid mean $N_{\mathrm{c}}$, the product of in-cloud $N_{\mathrm{c}}$ and cloud fraction also increases. Overall, both $N_{\mathrm{c}}$ and LWP increase in the high $\mathrm{BB}$ experiments due to delayed precipitation, particularly in 

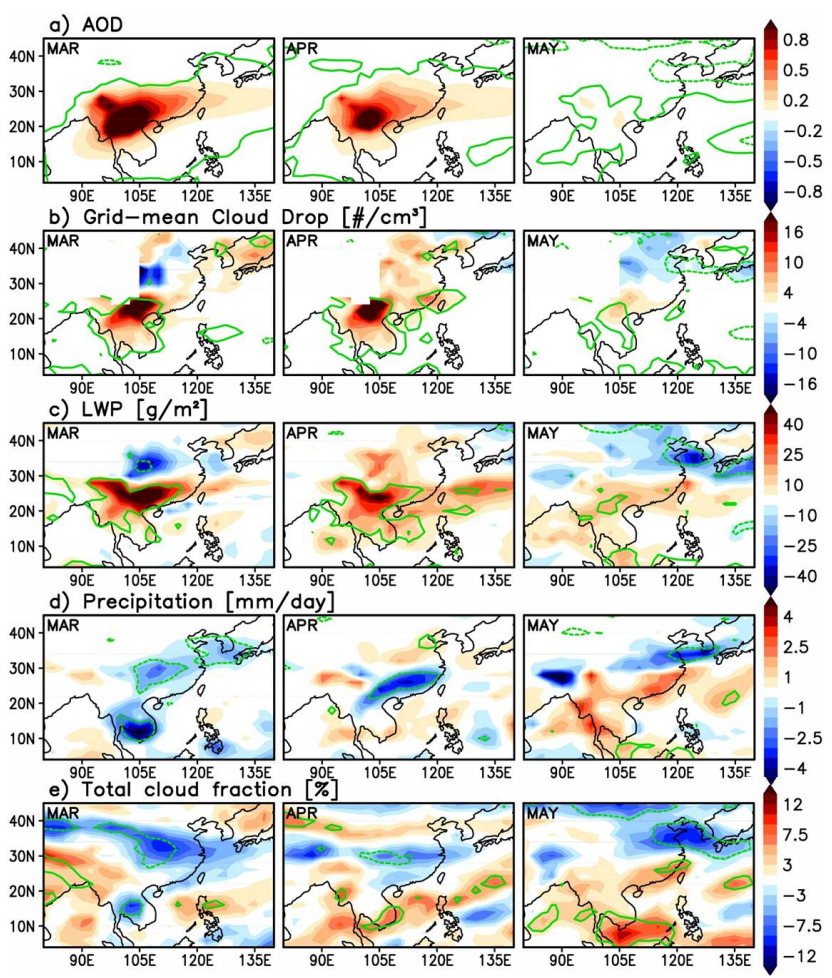

Figure 5. HighBoth minus ZeroBoth representing BBA effects on (a) aerosol optical depth, (b) grid mean cloud drop number concentration, (c) liquid water path (LWP), (d) precipitation and (e) total cloud fraction (\%) from COSP. Green contour mark regions of $>95 \%$ significant in a Student's $t$ test.

March and April. Still, some regions exhibit negative grid mean $N_{\mathrm{c}}$ and LWP anomalies, possibly because of reduced cloud fraction (Fig. 5e) due to reduced grid-scale relative humidity (RH) that determines cloud amount for stratiform clouds. The reduced RH is the outcome of larger stability of the lower atmosphere, which suppress rising motion.

While enhanced BB emission increases AOD, $\mathrm{CCN}, N_{\mathrm{c}}$, and even $L_{\mathrm{c}}$, the relationship is not linear. Increased $L_{\mathrm{c}}$ eventually creates a tendency for higher autoconversion and precipitation rates, which opposes the tendency of the increased $N_{\mathrm{c}}$ (Eq. 1). If we do not account for complex feedbacks, precipitation near the $\mathrm{BB}$ emission source can be expected to decrease if the increased $N_{\mathrm{c}}$ effect is stronger than the enhanced $L_{\mathrm{c}}$ effect, as shown in Fig. $5 \mathrm{~d}$ for March and April. While the satellite data analysis suggests alternating negative-positive precipitation anomalies along the wind flow, a weak positive anomaly surrounds the simulated strong negative anomaly over the South China Sea and northern China in April (Fig. 5d). This may be explained by two possible mechanisms. Liquid cloud water gets transported downstream instead of precipitating out locally because of suppressed autoconversion, while reduced local precipitation creates favorable circulation conditions for precipitation downwind. Meanwhile, a statistically significant anomaly of precipitation is found in May, suggesting that large BB emission in March and April can have a delayed effect even in regions far away from the source. Microphysical processes may therefore not be the only mechanism that reduces precipitation. The impact of BBA on May precipitation could be a combination of direct, indirect effects, and feedback processes initiated by aerosols in March and April. Further analysis of circulation changes is needed to distinguish whether this anomaly can be attributed to cloud microphysics or some other mechanism, a topic that we will address in Sect. 3.4.

\subsection{BB effects on the radiation budget}

BBA can change the radiation balance by both their direct and indirect effects. The direct effect of BBA consists of scattering (sulfate aerosols) and absorption (black carbon aerosols) of incoming solar radiation which cause surface cooling and atmospheric heating. As discussed in Sect. 3.2, the indirect effect of BBA comes from altering cloud optical properties like $R_{\text {eff }}$ and cloud amount which modify the net (= shortwave + longwave) radiation budget at the top of the atmosphere (TOA), atmosphere (ATM), and surface (SFC). Figure 6 illustrates the magnitude of the net radiation change at TOA, ATM, and SFC due to both direct and indirect aerosol effects, primarily due to changes in shortwave (SW) radiation. Each map shows the monthly mean difference between HighBoth and ZeroBoth experiments from March to May with red (blue) indicating heating (cooling) anomalies by aerosol, and green contours delineating the areas of statistically significant change. The overall net radiative effect of BBA is TOA/SFC cooling, and ATM heating near the source region, but its interpretation requires further scrutiny because contributions to net radiation change also come from circulation changes and associated feedbacks. The ATM heating in March and April provides a clearer signal of direct effects since the radiative heating comes almost exclusively from aerosol absorption, while TOA and SFC cooling comes from both direct and indirect aerosol effects. In May there is little aerosol direct effect, but a significant anomaly signal exists at the TOA and SFC due to feedbacks from circulation changes. When examining TOA and SFC radiation fields in May, the dipole pattern seen near the east coast of China and Korea is due to cloud fraction change (Fig. 5e) consistent with the precipitation change shown in Fig. 5d, and discussed further in the following section.

Table 2 shows the differences between HighBoth and ZeroBoth experiments of the net downward (down minus up) fluxes in March when BBA peaks, regionally averaged across the emission control region. Aerosol radiative effects are much larger in the SW than the longwave (LW), so most of the net radiation change comes from SW effects. The corresponding clear sky fluxes demonstrate that BBA increases SW reflectance, but also absorbance, because large fractions of BBA are composed by carbonaceous aerosols, which are 

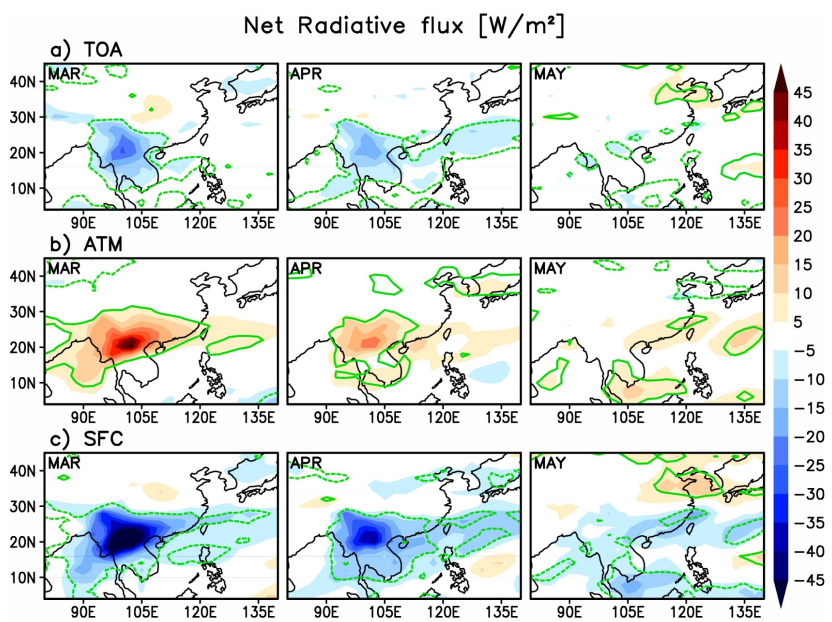

Figure 6. Same layout as in Fig. 5, but for net radiative fluxes at (a) top of the atmosphere, (b) column atmosphere, and (c) surface.

Table 2. Radiative flux change $\left(\mathrm{W} \mathrm{m}^{-2}\right)$ by BBA: numbers indicate the difference between HighBoth and ZeroBoth experiments in March and April, regionally averaged from 90 to $110^{\circ} \mathrm{E}$ and from 12 to $30^{\circ} \mathrm{N}$ only including land grid (emission control region). All fluxes are net downward, which means upward fluxes are subtracted from downward fluxes.

\begin{tabular}{lrrr}
\hline & TOA & ATM & SFC \\
\hline SW, all sky & -9.5 & 15.1 & -24.6 \\
SW, clear sky & -9.0 & 17.1 & -26.1 \\
LW, all sky & 0.3 & -2.5 & 2.8 \\
LW, clear sky & 1.2 & -1.0 & 2.2 \\
\hline
\end{tabular}

efficient absorbers of SW radiation. CRE is defined as

$\mathrm{CRE}=F_{\text {all }- \text { sky }}-F_{\text {clear }- \text { sky }}$,

where $F$ is the net downward flux at the TOA or surface. The SW CRE change by BBA (the difference between all sky and clear sky in Table 2 - not shown) is, somewhat surprisingly, positive at the surface (weaker SW CRE for the HighBoth experiment). Despite LWP increases (Fig. 5c) and

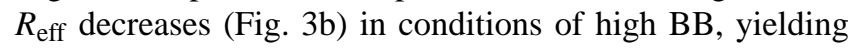
an average optical thickness increase of $46 \%$ for the cloudy part of the BBA source region, decreased total cloud fraction (Fig. 5e) due to circulation changes overcomes increased cloud brightness. So, the total indirect effect, namely $R_{\text {eff }}$ decreases (classic "Twomey effect"), accompanying LWP increases and any resulting cloud feedbacks, seem to counteract the direct aerosol effect in these GEOS-5 experiments.

\subsection{Temperature, moisture, and circulation changes}

In this section we discuss meteorological the consequences of the BBA radiative effects, which we have shown to lead to surface cooling and atmospheric heating. The surface tem- perature anomaly due to BBA is plotted in Fig. 7 and can be seen to be very significant near the source region in March and April. Weak negative anomalies also appear in May, but are mostly insignificant statistically. The vertical profile of temperature change (black line) by $\mathrm{BB}$, regionally averaged from 100 to $120^{\circ} \mathrm{E}$ and from 18 to $30^{\circ} \mathrm{N}$ (cf. red box in Fig. 7), is plotted in Fig. 8. This profile is obtained as the difference between the HighBoth and ZeroBoth experiments in March and April when the decrease of precipitation is significant, and reveals the presence of a cooling signal from the surface all the way up to the $250 \mathrm{hPa}$ level. In order to better understand what causes the temperature change, the model's major heating/cooling rate contributions are shown in Fig. 8. The orange line shows the SW heating rate $\left(\mathrm{K} \mathrm{day}^{-1}\right)$ anomaly, the red line the $\mathrm{LW}$ heating rate anomaly, and the blue line the anomaly of the heating rate due to the model's moist physics, namely large-scale condensation and convective processes. As expected, SW radiation heats the atmosphere near the height of the aerosol layer (Fig. 4). The reason the temperature profile does not cross over to the positive side is due to other contributors to temperature change, namely LW and moist physics, both of which cool the low and middle troposphere. The increase in LW cooling is a consequence of increased cloud liquid water between 800 to $600 \mathrm{hPa}$ due to aerosol-induced changes in cloud microphysical processes. Although the magnitude of LW cooling is only about a quarter of the SW heating, it has an impact since LW cooling occurs at the time and location of SW heating, because of liquid water and BBA collocation.

The major factor contributing to the negative temperature anomaly is the reduced moist heating, the most significant change of all the heating rate components of the model's physics. A negative moist physics heating rate anomaly translates to subdued cloud formation by large-scale condensation and even moist convection. In the area of interest, March precipitation mostly comes from large-scale condensation, while in April there is some contribution from moist convection. The reduced convective precipitation in April, accounting for about $40 \%$ of the total precipitation reduction, can be explained by changes in the vertical temperature gradient. BBA direct radiative effects make the surface cooler and the $700 \mathrm{hPa}$ level warmer, thus decreasing lowlevel atmospheric instability as seen in the vertical temperature profile anomaly; even though the overall temperature change is negative (cooling), a bump of temperature anomaly forms near $700 \mathrm{hPa}$ that suppresses the onset of moist convection.

Another important reason behind moist physics suppression, which can explain both large-scale condensation and moist convection, is change in atmospheric moisture content. Zonally averaged moisture and meridional circulation anomalies due to BBA within $100-120^{\circ} \mathrm{E}$ for March and April, and $110-140^{\circ} \mathrm{E}$ for May are plotted in Fig. 9. The blue shading, indicating dry anomaly, spreads over the 20 $30^{\circ} \mathrm{N}$ latitude zone where the BBA sources are located. A 


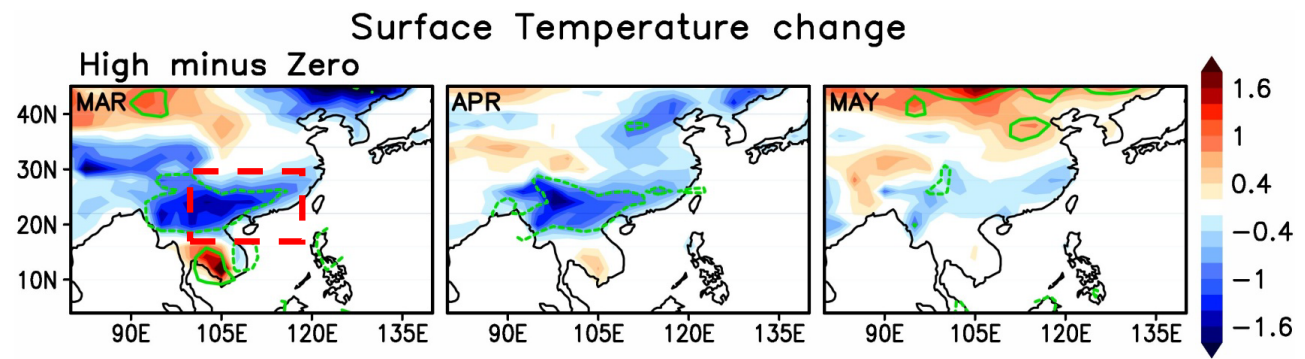

Figure 7. Same layout as in Fig. 5, but for surface temperature (K). Red dashed domain is for area-averaged fields in Fig. 8 and Table 4.

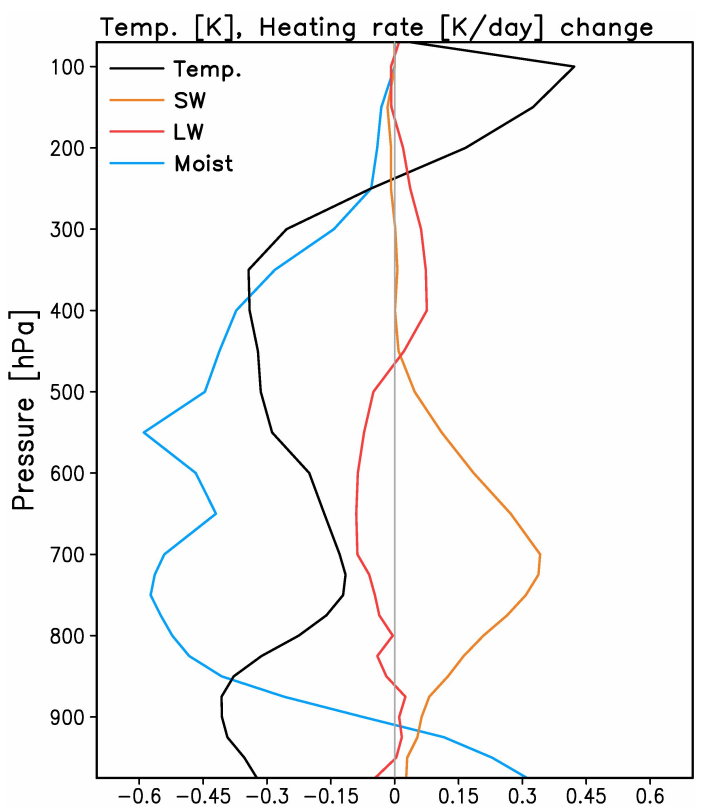

Figure 8. Vertical profile of temperature $(\mathrm{K})$ and heating rate $\left(\mathrm{K} \mathrm{day}^{-1}\right)$ differences between HighBoth and ZeroBoth simulations for March and April when precipitation decrease is significant; the averaging region is 100 to $120^{\circ} \mathrm{E}$ and 18 to $30^{\circ} \mathrm{N}$ and is marked in Fig. 7. Black, orange, red and blue lines represent temperature, SW heating rate, LW heating rate, and the heating rate due to the model's moist physics, respectively.

few factors play a role in making this region drier. One is reduced surface evaporation (Fig. 10) in the region of negative surface temperature anomaly. The other is circulation changes, specifically the substantial downward and southward flow anomalies induced by BBA. While the downward anomaly could be the result of reduced moist activity, the accompanying southward anomaly may actually be the cause of reduced moisture transport from low latitudes. The column-integrated moisture convergence anomaly (not shown) in the region where precipitation decreases is negative with some degree of statistical significance, albeit less than surface evaporation (Fig. 10). Another possible cause for overall drying is the decreased precipitation itself, implying positive feedback. Because of the BBA indirect effect, reduced autoconversion leaves behind more in-cloud water, which advects downwind instead of being converted into local precipitation, resulting in a reduced supply of moisture to the levels underneath and creating a feedback loop where weaker latent heat flux at the surface causes further decreases in precipitation.

Several mechanisms can potentially reduce precipitation in the downwind side of an active BB region. Cloud microphysics can delay the precipitation process by slowing down autoconversion, and then radiation can help make the area stable and dry, all conditions unfavorable for vigorous moist processes. Moreover, dry anomalies can be the result of cloud microphysics as well as in lack of rain and its evaporation. Likewise, a number of other variables may be changing in the same direction due to direct BBA effects on radiation and the indirect effects on cloud microphysics. Both effects cause SW dimming at the surface, low-level drying, and decreased precipitation. Separating microphysical from radiative effects is thus a worthwhile objective which we pursue in the following section.

\subsection{Quantitative breakdowns of direct and indirect effects}

In the previous sections, all the results explaining aerosol effects were based on HighBoth and ZeroBoth experiments, the first including BBA from a high-emission year and the latter entirely neglecting BBA emissions from the area of strongest fire activity. The GEOS-5 AGCM accounted for both direct effects in its radiative transfer routines and indirect effects in its cloud microphysics routines. Differences between the two experiments capture both aerosol direct and indirect effects (as well as feedbacks), in other words, combined effects (CE). In two other experimental sets, the 'HighInd' and ZeroInd experiments, direct effects of aerosol on radiation are ignored (globally), leaving only the indirect effect (IE) of BBA to be diagnosed as the difference between the two Ind experiments. Our diagnostic approach to separate the direct and indirect aerosol effects of a rather complex regional climatic response consists of comparing key variables from "CE" and "IE" differences, both including feedback from circulation changes. 


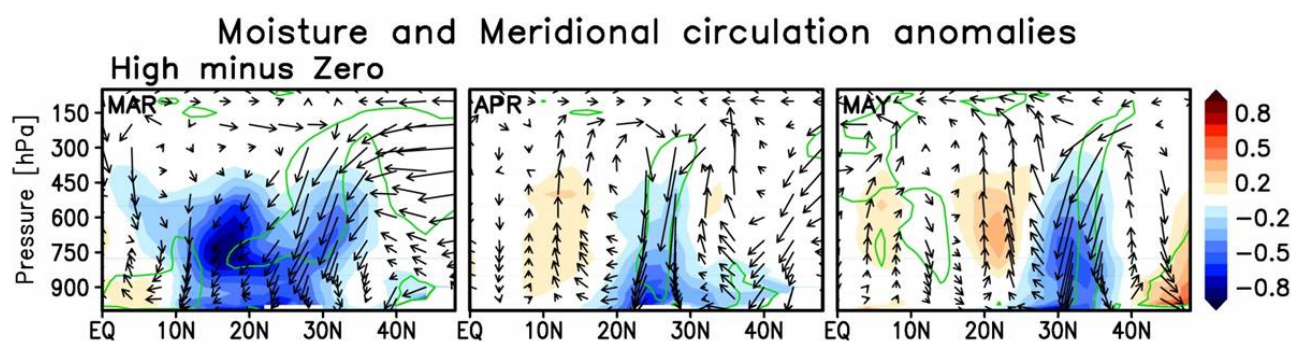

Figure 9. Zonally averaged profiles of moisture (shading) and meridional circulation anomalies (vectors, horizontal component is for meridional wind anomaly, vertical component is for pressure velocity) from HighBoth minus ZeroBoth experiments over the longitude sector $100-120^{\circ} \mathrm{E}$ for March and April, and sector $110-140^{\circ} \mathrm{E}$ for May. Units of pressure velocity, meridional wind, and water vapor mixing ratio are $10^{-2} \mathrm{~Pa} \mathrm{~s}^{-1}, \mathrm{~m} \mathrm{~s}^{-1}$, and $\mathrm{g} \mathrm{kg}^{-1}$, respectively.

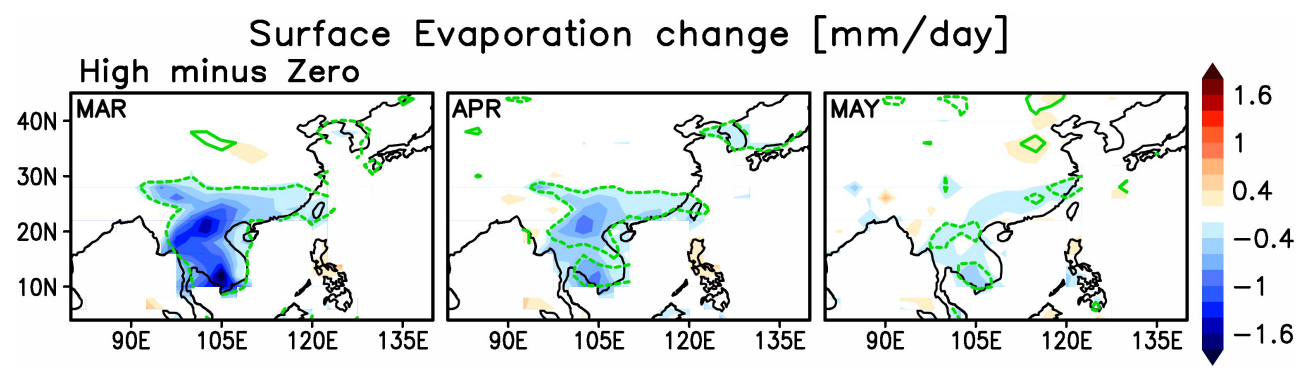

Figure 10. Similar to Fig. 5, but for surface evaporation $\left(\mathrm{mm} \mathrm{day}^{-1}\right)$.

Table 3 shows the radiative fluxes in the same way as Table 2, but for "IE" and "CE minus IE". Evidently, CE of TOA and SFC SW fluxes and atmospheric column SW absorption are much larger than the corresponding IE of aerosols on SW. This implies a much stronger contribution of the direct effect (DE) of BBA in CE and makes sense because BBAs have large AOD over the high-emission regions. Moreover, BBA effects on radiation in the $\mathrm{CE}$ runs are quite similar for clearsky and all-sky conditions, as pointed out earlier in Sect. 3.3. This provides further support for the notion that the IE due to BBA is an order of magnitude smaller on the SW and net radiation compared to the corresponding DE of aerosols as a component of CE. Net radiation change by IE turns out small because it depends on both cloud fraction (which depends on cloud production, cloud dissipation, and cloud advective tendencies) and cloud optical thickness (which depends on $\mathrm{CCN}$ and cloud water removal by precipitation). In ZeroInd, the (BBA-independent) cloud fraction increases while the cloud optical thickness decreases compared to HighInd simulations.

One of the interesting features of the BBA signal is decreased precipitation over the downwind side of the source. The separation of "CE" and "IE" impacts on precipitation would be interesting to study for this area. To minimize feedback contributions, we focus on variables that are primarily forced directly during the March and April time frame and near the source region, in particular 100 to $120^{\circ} \mathrm{E}$ and 18 to $30^{\circ} \mathrm{N}$. Table 4 provides the spatiotemporal aver-
Table 3. Radiative flux change $\left(\mathrm{W} \mathrm{m}^{-2}\right)$ by indirect effect of BBA, and the differences from Table 2. "IE" indicates the difference between HighInd and ZeroInd experiments, "CE" indicates the difference between HighBoth and ZeroBoth experiments, while the others are the same as Table 2 .

\begin{tabular}{lrrrrrr}
\hline & \multicolumn{2}{c}{ TOA } & \multicolumn{2}{c}{ ATM } & \multicolumn{2}{c}{ SFC } \\
\hline & IE & CE-IE & IE & CE-IE & IE & CE-IE \\
SW, all sky & 0.5 & -10 & 0.0 & 15.1 & 0.5 & -25.1 \\
SW, clear sky & -0.3 & -8.7 & -0.3 & 17.4 & 0.0 & -26.1 \\
LW, all sky & -2.1 & 2.4 & 0.8 & -3.3 & -1.3 & 4.1 \\
LW, clear sky & -0.4 & 1.6 & 0.7 & -1.7 & -1.1 & 3.3 \\
\hline
\end{tabular}

ages of these $\mathrm{CE}$ and IE breakdowns. While the $\mathrm{CE}$ precipitation reduction in HighBoth minus ZeroBoth BBA is $1.08 \mathrm{~mm} \mathrm{day}^{-1}$, the corresponding IE precipitation reduction is $0.77 \mathrm{~mm} \mathrm{day}^{-1}$ only. For a linear system, one would attribute the $0.31 \mathrm{~mm}^{-1} \mathrm{yy}^{-1}$ reduction corresponding to the $\mathrm{CE}$ minus IE difference, to the direct aerosol effect, but we are well aware that linearity is not necessarily a good assumption, so we view the differences as representing add-on direct effects that also contain effects of interactive circulation changes. Even though the IE averages do not show much change in the simulated surface temperature and evaporation of the boxed region, IE does have a prominent role in decreasing surface precipitation, which is caused not only by autoconversion reduction, but also by low-level drying due to SW dimming in cloudy areas. In other words, the suppressed 
Table 4. Analysis of combined effects (CE, Direct+Indirect) and only indirect effect (IE).

\begin{tabular}{lrr}
\hline $\begin{array}{l}\text { Aerosol } \\
\text { effect }\end{array}$ & $\begin{array}{r}\text { Combined } \\
\text { effect }\end{array}$ & $\begin{array}{r}\text { Indirect } \\
\text { effect }\end{array}$ \\
\hline Precipitation $^{\mathrm{a}}\left(\mathrm{mm} \mathrm{day}^{-1}\right)$ & -1.08 & -0.77 \\
Surface temperature $^{\mathrm{a}}(\mathrm{K})$ & -0.59 & 0.09 \\
Surface evaporation $^{\mathrm{a}}\left(\mathrm{mm} \mathrm{day}^{-1}\right)$ & -0.25 & 0.07 \\
Moisture $^{\mathrm{b}}\left(\mathrm{g} \mathrm{kg}^{-1}\right)$ & -0.38 & -0.23 \\
Moist heating rate $^{\mathrm{b}}\left(\mathrm{K} \mathrm{day}^{-1}\right)$ & -0.29 & -0.16 \\
Temperature $^{\mathrm{b}}(\mathrm{K})$ & -0.24 & -0.07 \\
\hline
\end{tabular}

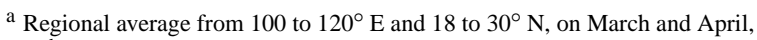
and ${ }^{b} 975$ to $500 \mathrm{hPa}$ vertical.

autoconversion that follows $\mathrm{CCN}$ and $N_{\mathrm{c}}$ increases due to the presence of additional BBA in the IE simulations and decreases precipitation, which creates a dry anomaly in the atmosphere beneath the precipitating cloud due to reduced evaporation of rain. In comparison, the DE as a part of CE has a more straightforward effect on the moisture supply that can be traced to atmospheric stabilization and reduced surface temperature due to surface cooling. So while both $\mathrm{CE}$ and IE tend to reduce precipitation, the mechanisms can differ overall, despite sharing the common processes of slower autoconversion and low-level drying.

\section{Summary and discussion}

An aerosol impact study including both the direct and indirect effects focusing on the Southeast Asia pre-monsoon season is conducted based on simulations using the GEOS5 AGCM with double moment cloud microphysics called McRAS-AC, interactive GOCART aerosol model, advanced radiative transfer package RRTMG applying the Monte Carlo Independent Column Approximation, and the CFMIP Observation Simulator Package (COSP). Analysis of GEOS-5 integrations with and without $\mathrm{BB}$ emission allows us to separate the responses of clouds and precipitation to aerosol from those due to changes in meteorological fields. Our analysis indicates that plausible reasons for the reduced precipitation are (a) vertical stabilization by atmospheric heating aloft accompanied by surface cooling due to the shortwave scattering and absorption by the BBA; (b) less efficient autoconversion despite liquid water increases due to increased cloud droplet number concentration; and (c) suppressed moist processes due to atmospheric drying. With properly designed experiments we managed to separate the impacts of direct and indirect effects. While vertical stabilization is traced to direct aerosol-radiation interaction, which causes rapid cloud adjustments (commonly referred to as the "semi-direct effect") because of depressed dynamical forcing, and the reduced autoconversion rate is primarily a consequence of aerosol-



Figure 11. Zonal mean temperature $(\mathrm{K})$ and wind $\left(\mathrm{m} \mathrm{s}^{-1}\right)$ differences between HighBoth and Zero Both BBA for $110-140^{\circ} \mathrm{E}$ in May. Green contour identifies regions with $>95 \%$ significant differences according to the Student's $t$ test. Black contour on (b) is zonal mean wind in HighBoth run.

cloud interaction (the indirect effect), the drying of the lower and middle troposphere is caused by both.

An interesting, and somewhat unexpected, consequence of enhanced BBAs is the May precipitation anomaly near the Korean peninsula shown in Fig. 5d. Since BB is not a major factor in May aerosol loadings, the precipitation anomaly could be due to circulation and land surface changes triggered by BB in the preceding month. In March and April, the surface temperature over Southeast Asia drops significantly due to the combined direct and indirect solar dimming effect of BBA and this reduces the meridional temperature gradient. Figure 9 shows that the overall circulation anomaly heads south in March and April. The May circulation anomaly exhibits downward motion at $30^{\circ} \mathrm{N}$ and a little upward motion south of $30^{\circ} \mathrm{N}$. According to Kim et al. (2007) an upper level jet stream change can induce secondary circulation changes near the entrance of the jet core in East Asia. In their analysis, an initial surface cooling by the direct effect of sulfate aerosol results in a reduced north-south thermal gradient. Figure 11a shows a similar weakened meridional temperature gradient change due to surface cooling found in March and April. This reduced gradient weakens the zonal wind shear through the thermal wind relationship, and slows down the westerly jet stream (Fig. 11b). The deceleration causes ageostrophic meridional winds and, in this case, anomalous sinking motion at $30^{\circ} \mathrm{N}$ (see Fig. 9, May), conditions that are less favorable for precipitation. Although Kim et al. (2007) account only for direct forcing of aerosol, the circulation anomalies induced by the BBA emissions of this study are similar, because indirect effects did not affect much the surface forcing in CE simulations.

While this study provided some confirmation that our BB sensitivity in the model looks similar to that from the MODIS analysis, the "Zero" BB assumption is admittedly extreme. So the year-to-year change of meteorological fields by BBA could be weaker than suggested by the results shown here. But given the plausibility of how the model's mechanisms operate, there is good possibility that real conditions would 
be consistent with the overall tendencies of the model. Still, there is much room for further development of the GEOS-5 model towards more realism. For example, phenomena such as aerosol-induced convective invigoration (Rosenfeld et al., 2008) cannot be properly reproduced in our model because heat release due to freezing does not affect the convective mass flux. This process could be better represented in a bulk mass flux convection scheme (e.g., Kim and Kang 2012), but it remains to be seen whether its inclusion in such a scheme would ultimately affect overall convective activity in a substantial way. Evidently, further refinements and cloud model validations are needed for a better understanding of the role of aerosol-convection interactions in the seasonal development of the summer monsoon. Our method of separating direct and indirect aerosol effects may be imperfect, but no better alternative currently exists given present modeling limitations. Regardless, we believe that this study provides a foundation on which to develop better methodologies to properly distinguish direct and indirect effect sensitivity to aerosols in large-scale models.

Acknowledgements. Funding from NASA's Modeling Analysis and Prediction (MAP) program managed by D. Considine, and from the Interdisciplinary Research in Earth Science (IDS) program (Water and Energy Cycle Impacts of Biomass Burning subelement) managed by Hal Maring is gratefully acknowledged. I.-S. Kang was supported by the National Research Foundation of Korea (NRF) grant funded by the Korean government (MEST) (NRF-2012M1A2A2671775) and the BK21 program.

Edited by: J. Ma

\section{References}

Albrecht, B.: Aerosols, Cloud Microphysics, and Fractional Cloudiness, Science, 245, 1227-1230, doi:10.1126/science.245.4923.1227, 1989.

Barahona, D. and Nenes, A.: Parameterizing the competition between homogeneous and heterogeneous freezing in cirrus cloud formation - monodisperse ice nuclei, Atmos. Chem. Phys., 9, 369-381, doi:10.5194/acp-9-369-2009, 2009a.

Barahona, D. and Nenes, A.: Parameterizing the competition between homogeneous and heterogeneous freezing in ice cloud formation - polydisperse ice nuclei, Atmos. Chem. Phys., 9, 59335948, doi:10.5194/acp-9-5933-2009, 2009b.

Bollasina, M., Ming, Y., and Ramaswamy, V.: Anthropogenic Aerosols and the Weakening of the South Asian Summer Monsoon, Science, 334, 502-505, doi:10.1126/science.1204994, 2011.

Chin, M., Ginoux, P., Kinne, S., Torres, O., Holben, B., Duncan, B., Martin, R., Logan, J., Higurashi, A., and Nakajima, T.: Tropospheric aerosol optical thickness from the GOCART model and comparisons with satellite and Sun photometer measurements, J. Atmos. Sci., 59, 461-483, doi:10.1175/15200469(2002)059<0461:TAOTFT>2.0.CO;2, 2002.
Chu, D., Kaufman, Y., Ichoku, C., Remer, L., Tanre, D., and Holben, B.: Validation of MODIS aerosol optical depth retrieval over land, Geophy. Res. Lett., 29, 1617, doi:10.1029/2001GL013205, 2002.

Chung, C. and Ramanathan, V.: Weakening of North Indian SST gradients and the monsoon rainfall in India and the Sahel, J. Climate, 19, 2036-2045, doi:10.1175/JCLI3820.1, 2006.

Clough, S., Shephard, M., Mlawer, E., Delamere, J., Iacono, M., Cady-Pereira, K., Boukabara, S., and Brown, P.: Atmospheric radiative transfer modeling: a summary of the AER codes, J. Quant. Spec. Ra., 91, 233-244, doi:10.1016/j.jqsrt.2004.05.058, 2005.

Colarco, P., da Silva, A., Chin, M., and Diehl, T.: Online simulations of global aerosol distributions in the NASA GEOS-4 model and comparisons to satellite and ground-based aerosol optical depth, J. Geophys. Res.-Atmos., 115, D14207, doi:10.1029/2009JD012820, 2010.

Darmenov, A. and da Silva, A.: The Quick Fire Emissions Dataset (QFED) - Documentation of versions 2.1, 2.2 and 2.4., NASA Technical Report Series on Global Modeling and Data Assimilation, NASA TM-2013-104606, Vol. 32, 183 pp., 2013.

Fountoukis, C. and Nenes, A.: Continued development of a cloud droplet formation parameterization for global climate models, J. Geophys. Res.-Atmos., 110, D11212, doi:10.1029/2004JD005591, 2005

Ganguly, D., Rasch, P., Wang, H., and Yoon, J.: Climate response of the South Asian monsoon system to anthropogenic aerosols, J. Geophys. Res.-Atmos., 117, D13209, doi:10.1029/2012JD017508, 2012.

Gautam, R., Hsu, N., Eck, T., Holben, B., Janjai, S., Jantarach, T., Tsay, S., and Lau, W.: Characterization of aerosols over the Indochina peninsula from satellite-surface observations during biomass burning pre-monsoon season, Atmos. Environ., 78, 5159, doi:10.1016/j.atmosenv.2012.05.038, 2013.

Guo, L., Highwood, E. J., Shaffrey, L. C., and Turner, A. G.: The effect of regional changes in anthropogenic aerosols on rainfall of the East Asian Summer Monsoon, Atmos. Chem. Phys., 13, 1521-1534, doi:10.5194/acp-13-1521-2013, 2013.

Huffman, G., Adler, R., Morrissey, M., Bolvin, D., Curtis, S., Joyce, R., McGavock, B., and Susskind, J.: Global precipitation at one-degree daily resolution from multisatellite observations, J. Hydrometeorol., 2, 36-50, doi:10.1175/15257541(2001)002<0036:GPAODD>2.0.CO;2, 2001.

Ichoku, C., Giglio, L., Wooster, M., and Remer, L.: Global characterization of biomass-burning patterns using satellite measurements of fire radiative energy, Remote Sens. Environ., 112, 2950-2962, doi:10.1016/j.rse.2008.02.009, 2008.

Kaufman, Y. and Koren, I.: Smoke and pollution aerosol effect on cloud cover, Science, 313, 655-658, doi:10.1126/science.1126232, 2006.

Kaufman, Y., Koren, I., Remer, L., Rosenfeld, D., and Rudich, Y.: The effect of smoke, dust, and pollution aerosol on shallow cloud development over the Atlantic Ocean, P. Natl. Acad. Sci. USA, 102, 11207-11212, doi:10.1073/pnas.0505191102, 2005.

Kim, D. and Kang, I.-S.: A bulk mass flux convection scheme for climate model: description and moisture sensitivity, Clim. Dynam., 38, 411-429, doi:10.1007/s00382-010-0972-2, 2012.

Kim, M.-K., Lau, K.-M., Kim, K.-M., and Lee, W.: A GCM study of effects of radiative forcing of sulfate aerosol on large scale cir- 
culation and rainfall in East Asia during boreal spring, Geophys. Res. Lett., 34, L24701, doi:10.1029/2007GL031683, 2007.

Klein, S., Zhang, Y., Zelinka, M., Pincus, R., Boyle, J., and Gleckler, P.: Are climate model simulations of clouds improving? An evaluation using the ISCCP simulator, J. Geophys. Res.-Atmos., 118, 1329-1342, doi:10.1002/jgrd.50141, 2013.

Lau, K.-M. and Kim, K.-M.: Observational relationships between aerosol and Asian monsoon rainfall, and circulation, Geophys. Res. Lett., 33, L21810, doi:10.1029/2006GL027546, 2006.

Lau, K.-M. and Kim, K.-M.: Impact of aerosols on the Asian monsoon - an interim assessment, in: Climate Change: Multidecadal and Beyond, edited by: Chang, C.-P., Ghil, M., Latif, M., and Wallace, M., in press, World Scientific, 2014.

Lau, K.-M., Kim, M.-K., and Kim, K.-M.: Asian summer monsoon anomalies induced by aerosol direct forcing: the role of the Tibetan Plateau, Clim. Dynam., 26, 855-864, doi:10.1007/s00382006-0114-z, 2006.

Li, Z., Niu, F., Fan, J., Liu, Y., Rosenfeld, D., and Ding, Y.: Long-term impacts of aerosols on the vertical development of clouds and precipitation, Nat. Geosci., 4, 888-894, doi:10.1038/NGEO1313, 2011.

Lin, C.-Y., Hsu, H.-m., Lee, Y. H., Kuo, C. H., Sheng, Y.-F., and Chu, D. A.: A new transport mechanism of biomass burning from Indochina as identified by modeling studies, Atmos. Chem. Phys., 9, 7901-7911, doi:10.5194/acp-9-7901-2009, 2009.

Lim, K.-S. S., Fan, J., Leung, L. R., Ma, P.-L., Singh, B., Zhao, C., Zhang, Y., Zhang, G., and Song, X.: Investigation of aerosol indirect effects using a cumulus microphysics parameterization in a regional climate model, J. Geophys. Res.-Atmos., 119, 906926, doi:10.1002/2013JD020958, 2014.

Meehl, G., Arblaster, J., and Collins, W.: Effects of black carbon aerosols on the Indian monsoon, J. Climate, 21, 2869-2882, doi:10.1175/2007JCLI1777.1, 2008.

Molod, A., Takacs, L., Suarez, M. J., Bacmeister, J., Song, I.-S., and Eichmann, A.: GEOS-5 Atmospheric General Circulation Model: mean climate development from MERRA to Fortuna, Tech. Memo., NASA Goddard Space Flight Center, MD, 115 pp., 2012.

Moorthy, K., Babu, S., Manoj, M., and Satheesh, S.: Buildup of aerosols over the Indian Region, Geophys. Res. Lett., 40, 10111014, doi:10.1002/grl.50165, 2013.

Oreopoulos, L., Lee, D., Sud, Y. C., and Suarez, M. J.: Radiative impacts of cloud heterogeneity and overlap in an atmospheric General Circulation Model, Atmos. Chem. Phys., 12, 9097-9111, doi:10.5194/acp-12-9097-2012, 2012.

Petters, M., Carrico, C., Kreidenweis, S., Prenni, A., DeMott, P., Collett, J., and Moosmuller, H.: Cloud condensation nucleation activity of biomass burning aerosol, J. Geophys. Res.-Atmos., 114, D22205, doi:10.1029/2009JD012353, 2009.

Pincus, R., Barker, H., and Morcrette, J.: A fast, flexible, approximate technique for computing radiative transfer in inhomogeneous cloud fields, J. Geophys. Res.-Atmos., 108, 4376, doi:10.1029/2002JD003322, 2003.

Platnick, S., King, M., Ackerman, S., Menzel, W., Baum, B., Riedi, J., and Frey, R.: The MODIS cloud products: Algorithms and examples from Terra, Ieee T. Geosci. Remote, 41, 459-473, doi:10.1109/TGRS.2002.808301, 2003.

Quaas, J., Stevens, B., Stier, P., and Lohmann, U.: Interpreting the cloud cover - aerosol optical depth relationship found in satellite data using a general circulation model, Atmos. Chem. Phys., 10, 6129-6135, doi:10.5194/acp-10-6129-2010, 2010.

Ramanathan, V., Chung, C., Kim, D., Bettge, T., Buja, L., Kiehl, J., Washington, W., Fu, Q., Sikka, D., and Wild, M.: Atmospheric brown clouds: Impacts on South Asian climate and hydrological cycle, P. Natl. Acad. Sci. USA, 102, 5326-5333, doi:10.1073/pnas.0500656102, 2005.

Rienecker M. M., Suarez, M. J., Todling R., Bacmeister J., Takacs L., Liu H.-C., Gu W., Sienkiewicz M., Koster, R. D., Gelaro, R., Stajner, I., and Nielsen, J. E.: The GEOS-5 Data Assimilation System Documentation of Versions 1 5.0.1, 5.1.0, and 5.2.0. NASA/TM-2008-2 104606, Vol. 27, 118 pp., 2008.

Roelofs, G.-J.: A steady-state analysis of the temperature responses of water vapor and aerosol lifetimes, Atmos. Chem. Phys., 13, 8245-8254, doi:10.5194/acp-13-8245-2013, 2013.

Rosenfeld, D., Lohmann, U., Raga, G., O’Dowd, C., Kulmala, M., Fuzzi, S., Reissell, A., and Andreae, M.: Flood or drought: How do aerosols affect precipitation?, Science, 321, 1309-1313, doi:10.1126/science.1160606, 2008.

Rotstayn, L., Ryan, B., and Katzfey, J.: A scheme for calculation of the liquid fraction in mixed-phase stratiform clouds in large-scale models, Mon. Weather Rev., 128, 1070-1088, doi:10.1175/15200493(2000)128<1070:ASFCOT>2.0.CO;2, 2000.

Seifert, A. and Beheng, K.: A double-moment parameterization for simulating autoconversion, accretion and selfcollection, Atmos. Res., 59, 265-281, doi:10.1016/S0169-8095(01)00126-0, 2001.

Seifert, A. and Beheng, K.: A two-moment cloud microphysics parameterization for mixed-phase clouds. Part 1: Model description, Meteorol. Atmos. Phys., 92, 45-66, doi:10.1007/s00703005-0112-4, 2006.

Sud, Y. C. and Lee, D.: Parameterization of aerosol indirect effect to complement McRAS cloud scheme and its evaluation with the 3year ARM-SGP analyzed data for single column models, Atmos. Res., 86, 105-125, doi:10.1016/j.atmosres.2007.03.007, 2007.

Sud, Y. C. and Walker, G.: Microphysics of Clouds with the Relaxed Arakawa-Schubert Scheme (McRAS). Part I: Design and evaluation with GATE Phase III data, J. Atmos. Sci., 56, 3196-3220, 1999.

Sud, Y. C. and Walker, G.: New upgrades to the microphysics and thermodynamics of clouds in McRAS: SCM and GCM evaluation of simulation biases in GEOS GCM, P. Natl. A. Sci. India A, 69, 543-565, 2003.

Sud, Y. C., Lee, D., Oreopoulos, L., Barahona, D., Nenes, A., and Suarez, M. J.: Performance of McRAS-AC in the GEOS5 AGCM: aerosol-cloud-microphysics, precipitation, cloud radiative effects, and circulation, Geosci. Model Dev., 6, 57-79, doi:10.5194/gmd-6-57-2013, 2013.

Sundqvist, H.: Parameterization of condensation and associated clouds in models for weather prediction and general circulation simulation, Physically based modeling and simulation of climate and climatic change, edited by: Schlesinger, M. E., Kluwer Academic Publishers, Dordrecht, the Netherlands, 433-461, 1988.

Tao, W., Chen, J., Li, Z., Wang, C., and Zhang, C.: Impact of aerosols on conective clouds and precipitation, Rev. Geophys., 50, doi:10.1029/2011RG000369, 2012.

Taylor, D.: Biomass burning, humans and climate change in Southeast Asia, Biodivers. Conserv., 19, 1025-1042, doi:10.1007/s10531-009-9756-6, 2010. 
Tosca, M. G., Randerson, J. T., Zender, C. S., Flanner, M. G., and Rasch, P. J.: Do biomass burning aerosols intensify drought in equatorial Asia during El Niño?, Atmos. Chem. Phys., 10, 35153528, doi:10.5194/acp-10-3515-2010, 2010.

Twomey, S.: The influence of pollution on the shortwave albedo of clouds, J. Atmos. Sci., 34, 1149-1152, 1977.
Wiedinmyer, C., Akagi, S. K., Yokelson, R. J., Emmons, L. K., AlSaadi, J. A., Orlando, J. J., and Soja, A. J.: The Fire INventory from NCAR (FINN): a high resolution global model to estimate the emissions from open burning, Geosci. Model Dev., 4, 625641, doi:10.5194/gmd-4-625-2011, 2011.

Wu, L., Su, H., and Jiang, J.: Regional simulation of aerosol impacts on precipitation during the East Asian summer monsoon, J. Geophys. Res.-Atmos., 118, 6454-6467, doi:10.1002/jgrd.50527, 2013. 